\title{
Exponential Function of a bounded Linear Operator on a Hilbert Space.
}

\author{
Radhi I. Mohammed *
}

Fatin A. Ahmed **

Received 28, May, 2013

Accepted 18, September, 2013

\begin{abstract}
:
In this paper, we introduce an exponential of an operator defined on a Hilbert space $\mathrm{H}$, and we study its properties and find some of properties of $\mathrm{T}$ inherited to exponential operator, sowe study the spectrum of exponential operatore ${ }^{T}$ according to the operator $\mathrm{T}$.
\end{abstract}

Keywords: Self-adjoint operator, positive operator, normal operator, quasinormal operator, binormaloperator hyponormal operator and compact operator.

\section{Introduction:}

LetB $(\mathrm{H})$ bea space of all bounded linear operator on a Hilbert space $\mathrm{H}$ (real or complex).

We introduced anew bounded linear operator defined on $\mathrm{H}$, as a limit of sequence or power series of linear operator T.Giaquinta;Modica in [1] gave a definition of an exponential operatore $^{\mathrm{T}}$ of a bounded linear operator $\mathrm{T}$ as the sum of power series of $\mathrm{T}$, and it started the properties of exponential operator of bounded linear operator $\mathrm{T}$. In this paper we study the inherited properties of $\mathrm{T}$ into the operator $\mathrm{e}^{\mathrm{T}}$, and the spectrum of exponential operatore $^{\mathrm{T}}$ according to the operator $\mathrm{T}$. Such properties of $\mathrm{T}$ can be found in [2],[3],[4],[5],[6],[7] and [8].

\section{Preminilaries:}

\section{Definition:}

Let $\mathrm{T} \in \mathrm{B}(\mathrm{H})$ thene $^{\mathrm{T}}: \mathrm{H} \rightarrow \mathrm{H}$ defines as $\mathrm{e}^{\mathrm{T}} \mathrm{x}=\sum_{\mathrm{n}=0}^{\infty} \frac{1}{\mathrm{n} !} \mathrm{T}^{\mathrm{n}} \mathrm{x} \quad$.So, we write $\mathrm{e}^{\mathrm{T}}=\sum_{\mathrm{n}=0}^{\infty} \frac{1}{\mathrm{n} !} \mathrm{T}^{\mathrm{n}}$.

We need to check the definition of exponential operator is well-define, i.e. The power series is convergent for each $\mathrm{x} \in \mathrm{H}$, by following propositionin [1] .

\section{Proposition:}

Let $\mathrm{H}$ be a Hilbert space and $\mathrm{T} \in \mathrm{B}(\mathrm{H})$. 1. If $\mathrm{f}(\mathrm{z})=\sum_{\mathrm{n}=0}^{\infty} \mathrm{a}_{\mathrm{n}} \mathrm{z}^{\mathrm{n}}$ be a power series with radius of convergence $R>$ 0 and $\|\mathrm{T}\| \leq \mathrm{R}$.

Then the series $\sum_{n=0}^{\infty} a_{n} T^{n}$ convergence in $\mathrm{B}(\mathrm{H})$ and define a linear continuous operator.

2. The series $\sum_{\mathrm{k}=0}^{\infty} \frac{1}{\mathrm{k} !} \mathrm{T}^{\mathrm{k}}$ converges in $\mathrm{B}(\mathrm{H})$ and define the linear continuous operator $\quad \mathrm{e}^{\mathrm{T}}=\sum_{\mathrm{k}=0}^{\infty} \frac{1}{\mathrm{k} !} \mathrm{T}^{\mathrm{k}}$.

\section{Examples:}

$1 . \mathrm{e}^{\mathrm{o}}=\mathrm{I}$,Where 0 is a zero operator and $I$ is an identity operator defined on $\mathrm{H}$.

2. $e^{I}=\sum_{n=0}^{\infty} \frac{1}{n !} I^{n}=\sum_{n=0}^{\infty} \frac{1}{n !} I=$ eI.

3. IfT is a nilpotent of degree $n \in N$, i.e. $\mathrm{T}^{\mathrm{n}}=0$ in [2], then $\mathrm{e}^{\mathrm{T}}=$ $\sum_{\mathrm{k}=0}^{\mathrm{n}-1} \frac{1}{\mathrm{k} !} \mathrm{T}^{\mathrm{k}}$,

$$
\mathrm{e}^{\mathrm{T}}=\sum_{\mathrm{n}=0}^{\infty} \frac{1}{\mathrm{n} !} \mathrm{T}^{\mathrm{n}}
$$

$$
=\mathrm{I}+\mathrm{T}+\frac{1}{2 !} \mathrm{T}^{2}+\cdots
$$

$+\frac{1}{(\mathrm{n}-\mathrm{m}) !} \mathrm{T}^{\mathrm{n}-1}$.

*Dept. of Mathematics, College of Science for Women, University of Baghdad 
This paper consists of three sections. Insection one we study some properties of an exponential operator on H.While, in section two we study some properties operator $\mathrm{T}$ on $\mathrm{H}$ inherited to operatore ${ }^{\mathrm{T}}$.In section three, we study the spectrum of exponential operatore $^{\mathrm{T}}$ according to the operator $\mathrm{T}$.

\section{Some properties of an Exponential operator on a Hilbert space H:}

In [1] Mariano gave some properties of $\mathrm{e}^{\mathrm{T}}$ without proof. In this section we present its proofs.

\section{Proposition (1.1)}

Let $\mathrm{T}, \mathrm{S} \in \mathrm{B}(\mathrm{H})$ we have the following properties of $\mathrm{e}^{\mathrm{T}}$ :

1. If $\mathrm{S}=\mathrm{S}$ T then $\mathrm{e}^{\mathrm{T}+\mathrm{S}}=\mathrm{e}^{\mathrm{T}} \mathrm{e}^{\mathrm{S}}=$ $\mathrm{e}^{\mathrm{S}} \mathrm{e}^{\mathrm{T}}$.

2. $\mathrm{e}^{\mathrm{T}} \mathrm{e}^{-\mathrm{T}}=\mathrm{I}$, and hence the inverse of $\mathrm{e}^{\mathrm{T}}$ is $\mathrm{e}^{-\mathrm{T}}$, i.e. $\left(\mathrm{e}^{\mathrm{T}}\right)^{-1}=\mathrm{e}^{-\mathrm{T}}$.

3. $\mathrm{e}^{(\alpha+\beta) \mathrm{T}}=\mathrm{e}^{\alpha \mathrm{T}} \mathrm{e}^{\beta \mathrm{T}}$, for any $\alpha, \beta$ scalar.

4. $\left\|\mathrm{e}^{\mathrm{T}}\right\| \leq \mathrm{e}^{\|\mathrm{T}\|}$.

5. $\left(\mathrm{e}^{\mathrm{T}}\right)^{*}=\mathrm{e}^{\mathrm{T}^{*}}$.

\section{Proof:}

1. By using of multiplication of absolutely convergent series we get :

$\mathrm{e}^{\mathrm{T}} \mathrm{e}^{\mathrm{S}}=\sum_{\mathrm{n}=\mathrm{o}}^{\infty} \frac{1}{\mathrm{n} !} \mathrm{T}^{\mathrm{n}} \sum_{\mathrm{m}=0}^{\infty} \frac{1}{\mathrm{~m} !} \mathrm{S}^{\mathrm{m}}=$ $\sum_{\mathrm{n}=0}^{\infty} \sum_{\mathrm{k}=\mathrm{o}}^{\mathrm{n}} \frac{1}{\mathrm{k} !(\mathrm{n}-\mathrm{k}) !} \mathrm{T}^{\mathrm{k}} \mathrm{S}^{\mathrm{n}-\mathrm{k}}=$

$\sum_{\mathrm{n}=0}^{\infty} \frac{1}{\mathrm{n} !} \sum_{\mathrm{k}=0}^{\mathrm{n}}\left(\begin{array}{l}\mathrm{n} \\ \mathrm{k}\end{array}\right) \mathrm{T}^{\mathrm{k}} \mathrm{S}^{\mathrm{n}-\mathrm{k}}=$

$\sum_{\mathrm{n}=0}^{\infty} \frac{1}{\mathrm{n} !}(\mathrm{T}+\mathrm{S})^{\mathrm{n}}$

$=\mathrm{e}^{\mathrm{T}+\mathrm{S}}$.

2. $\mathrm{e}^{\mathrm{T}} \mathrm{e}^{\mathrm{T}^{\mathrm{T}}}=\mathrm{e}^{\mathrm{T}+(-\mathrm{T})}=\mathrm{e}^{0}=\mathrm{I}$, by part (1) .

3. The result following by part one of this proposition.

4.

have $\left\|\sum_{\mathrm{k}=0}^{\mathrm{n}} \mathrm{T}^{\mathrm{k}}\right\| \leq$

$\sum_{\mathrm{k}=0}^{\mathrm{n}}\left\|\mathrm{T}^{\mathrm{k}}\right\| \leq \sum_{\mathrm{k}=0}^{\mathrm{n}}\|\mathrm{T}\|^{\mathrm{k}}$.
And $\left\|\sum_{\mathrm{k}=0}^{\mathrm{n}} \frac{1}{\mathrm{k} !} \mathrm{T}^{\mathrm{k}}\right\| \quad$ converges to $\left\|\mathrm{e}^{\mathrm{T}}\right\|$ and $\sum_{\mathrm{k}=0}^{\mathrm{n}} \frac{1}{\mathrm{k} !}\|\mathrm{T}\|^{\mathrm{k}}$ to $\mathrm{e}^{\|\mathrm{T}\|}$.So, we have $\left\|\mathrm{e}^{\mathrm{T}}\right\| \leq \mathrm{e}^{\|\mathrm{T}\|}$.

5. $\left(\mathrm{e}^{\mathrm{T}}\right)^{*}=\left(\sum_{\mathrm{n}=0}^{\infty} \frac{1}{\mathrm{n} !} \mathrm{T}^{\mathrm{n}}\right)^{*}=$ $\sum_{\mathrm{n}=0}^{\infty} \frac{1}{\mathrm{n} !}\left(\mathrm{T}^{\mathrm{n}}\right)^{*}=\sum_{\mathrm{n}=0}^{\infty} \frac{1}{\mathrm{n} !}\left(\mathrm{T}^{*}\right)^{\mathrm{n}}=\mathrm{e}^{\mathrm{T}^{*}}$.

There is another equivalent definition of an exponential operator of a bounded linear on a Hilbert space $\mathrm{H}$, as a limit of sequence of some bounded operators [1].

\section{Theorem (1.2)}

LetT be a bounded linear operator defined on a Hilbert space $\mathrm{H}$, then $\left(\mathrm{I}+\frac{1}{\mathrm{n}} \mathrm{T}\right)^{\mathrm{n}} \rightarrow \mathrm{e}^{\mathrm{T}}$.

The proof of this theorem can be found in [1]

\section{Main Results:}

In this section, we are going to give some properties of linear operators defined on a Hilbert space $\mathrm{H}$, that inherited an exponential operator many them: self-ajoint, positive, normral, quasinormal , hyponormal and compact.

\section{$\operatorname{Lemma}(2.1)[2]$}

1. If $\mathrm{T}$ is a self-adjoint operator. Then $\alpha \mathrm{T}$ is a self-adjoint, for all real number $\alpha$.

2. If $T, S$ are self-adjoint linear operators on $\mathrm{H}$. Then $\mathrm{T}+\mathrm{S}$ is a selfadjoint .

3. If T, Sare self-adjoint linear operators on $\mathrm{H}$. Then TS is a self adjoinet if and only if TS $=$ ST .

4. If $\mathrm{T}$ is a self-adjoinet operator. Then $^{\mathrm{n}}$ is a self-adjoint, too for any positive integer $n \geq 2$.

5. If $\left(T_{n}\right)$ is a sequence of bounded self-adjoint linear operators on $\mathrm{H}$, and $\mathrm{T}_{\mathrm{n}}$ converges to a linear operator $\mathrm{T}$. Then the operator $\mathrm{T}$ is also selfadjoint.

\section{Proposition (2.2)}


If $\mathrm{T}$ is a self-adjoint operator on a Hilbert space $H$, then so ise ${ }^{T}$.

\section{Proof:}

If $\mathrm{T}$ is self-adjoint operator and $\mathrm{n}$ any positive integer, we have that lemma (2.1) parts (1), (2) and (4)(I+ $\left.\frac{1}{\mathrm{n}} \mathrm{T}\right)^{\mathrm{n}}$ is aself-adjoint . But(I+ $\left.\frac{1}{\mathrm{n}} \mathrm{T}\right)^{\mathrm{n}}$ convergent to $\mathrm{e}^{\mathrm{T}}$, then by lemma (2.1) part (5) $\mathrm{e}^{\mathrm{T}}$ is self-adjoint .

\section{Definition(2.3)[2]}

Let $\mathrm{T} \in \mathrm{B}(\mathrm{H})$ be a self-adjoint operator, it is said a positive operator if $\mathrm{T} \geq 0$, i.e. $\langle\mathrm{Tx}, \mathrm{x}\rangle \geq 0$, for all $\mathrm{x}$ in $\mathrm{H}$.

\section{Lemma (2.4)[2]}

1. If $\mathrm{T}$ is a positive operator. Then $\alpha \mathrm{T}$ is a positive, each non negative scalar $\alpha$.

2. If $\mathrm{T}, \mathrm{S}$ are positive linear operators. Then $\mathrm{T}+\mathrm{S}$ is positive.

3. IfT, $S$ are positive linear operators andTS $=$ ST. Then TS is positive.

4. If $\mathrm{T}$ is a positive operator . Then $\mathrm{T}^{\mathrm{n}}$ is positive, too for any positive integer $\mathrm{n} \geq 2$.

5. The limit of a sequence of positive linear operators on $\mathrm{H}$, isapositive operator.

\section{Proposition (2.5)}

If $\mathrm{T}$ is a positiveoperator on a Hilbert space $\mathrm{H}$, then so ise $\mathrm{T}^{\mathrm{T}}$

\section{Proof :}

If $\mathrm{T}$ is a positiveoperator and $\mathrm{n}$ any positive integer, then by lemma (2.4) parts (1),(2) and (4) we have (I+ $\left.\frac{1}{n} \mathrm{~T}\right)^{\mathrm{n}}$ is a positive operator. But( $\mathrm{I}+$ $\left.\frac{1}{n} T\right)^{n}$ converges toe ${ }^{T}$, then by lemma (2.4) part (5)we have $\mathrm{e}^{\mathrm{T}}$ is positive.

\section{Remark (2.6)}

IfT is a skew-self-adjoint operator , i.e. $\mathrm{T}^{*}=-\mathrm{T}$ in $[2]$, thene $\mathrm{T}^{\mathrm{T}}$ may not be a skew, to see this, we have the following example:

Let $\mathrm{T}=2 \mathrm{iI}$ be a linear operator on a complex Hilbert space $\mathrm{H}$. We have
$\mathrm{T}^{*}=(2 \mathrm{iI})^{*}=-2 \mathrm{iI}=-\mathrm{T}$, hence $\mathrm{T}$ is a skew-self-adjoint operator . But $\left(\mathrm{e}^{\mathrm{T}}\right)^{*}=\left(\mathrm{e}^{2 \mathrm{iI}}\right)^{*}=\mathrm{e}^{(2 \mathrm{iI})^{*}}=$ $\mathrm{e}^{-2 \mathrm{iI}}$,i.e. $\mathrm{e}^{\mathrm{T}}$ is not a skew-self-adjoint.

\section{Proposition (2.7)}

If $\mathrm{T}$ is a normal operator on $\mathrm{H}$, thene $\mathrm{T}^{\mathrm{T}}$ is also normal .

\section{Proof :}

$\mathrm{T}$ is a normal operator $\mathrm{T} \mathrm{T}^{*}=\mathrm{T} \mathrm{T}^{*}$ in thisimplies by (1.1) part (1),we have: $\mathrm{e}^{\mathrm{T}} \mathrm{e}^{\mathrm{T}^{*}}=\mathrm{e}^{\mathrm{T}+\mathrm{T}^{*}}=\mathrm{e}^{\mathrm{T}^{*}+\mathrm{T}}=\mathrm{e}^{\mathrm{T}^{*}} \mathrm{e}^{\mathrm{T}}$, hence $\mathrm{e}^{\mathrm{T}}$ is normal.

\section{Definition (2.8)[3]}

Let Tbe a bounded linear operator on $\mathrm{H}$. It is called a quasinormal if $\mathrm{T}$ commutes with $\mathrm{T}^{*} \mathrm{~T}$, i.e. $\mathrm{T}\left(\mathrm{T}^{*} \mathrm{~T}\right)=\left(\mathrm{T}^{*}\right.$ T) $\mathrm{T}$

\section{Lemma (2.9)}

Let $\mathrm{T}, \mathrm{S} \quad \in \mathrm{B}(\mathrm{H}) \quad$ bequasinormal operators then :

1. $\alpha \mathrm{T}$ is a quasinormal,$\alpha$ for any scalar.

2. $\mathrm{T}+\mathrm{S}$ is aquasinormal with property that each commute with the adjoint of the other.

3. ST is a quasinormal if the following conditions are satisfied:

(i) $\mathrm{ST}=\mathrm{TS}$ (ii) $\mathrm{ST}^{*}=\mathrm{T}^{*} \mathrm{~S}$

4. The limit of a sequence ofquasinormal linear operators on $\mathrm{H}$, is aquasinormaloperator.

The proof of this lemma can be found in [2],[3]

\section{$\operatorname{Remark}(2.10)$}

By using mathematical induction and lemma (2.9) part (3), we have $\mathrm{T}^{\mathrm{n}}$ is quasionormal operator on a Hilbert space $\mathrm{H}$, for $\mathrm{n} \geq 2$.

\section{Proposition (2.11)}

Let $\mathrm{T}$ bea quasinormal operator on $\mathrm{H}$, then $\mathrm{e}^{\mathrm{T}}$ is also quasinormal .

\section{Proof :}

If $\mathrm{T}$ is a quasinormal operator and $\mathrm{n}$ any positive integer, then by lemma (2.9) parts (1),(2) and (2.10) we have $\left(\mathrm{I}+\frac{1}{\mathrm{n}} \mathrm{T}\right)^{\mathrm{n}}$ is a quasinormal operator. 
$\operatorname{But}\left(\mathrm{I}+\frac{1}{\mathrm{n}} \mathrm{T}\right)^{\mathrm{n}}$ converges toe ${ }^{\mathrm{T}}$, then by lemma (2.9) part (4), we have $\mathrm{e}^{\mathrm{T}}$ is quasinormal.

\section{Definition (2.12) [4]}

An operator $\mathrm{T}$ on $\mathrm{H}$ is said a binormalif $\mathrm{TT}^{*}$ commutes withT ${ }^{*} \mathrm{~T}$, i.e. $\left[\mathrm{TT}^{*}, \mathrm{~T}^{*} \mathrm{~T}\right]=0$

\section{Remark (2.13)}

If $\mathrm{T}$ is binormal operator on $\mathrm{H}$. Then $\mathrm{e}^{\mathrm{T}}$ may not be binormal, so we are going to

example to show this :

$$
\text { Let } T=\left(\begin{array}{ll}
0 & 1 \\
0 & 0
\end{array}\right) \text { can easily verify }
$$

that $\mathrm{T}$ be binormal $\operatorname{andT}^{2}=\left(\begin{array}{ll}0 & 0 \\ 0 & 0\end{array}\right)$, we have :

$\mathrm{e}^{\mathrm{T}}=\sum_{\mathrm{n}=0}^{\infty} \frac{1}{\mathrm{n} !} \mathrm{T}^{\mathrm{n}} \mathrm{x}=\mathrm{I}+\mathrm{T}=\left(\begin{array}{ll}1 & 1 \\ 0 & 1\end{array}\right)$, and $\mathrm{e}^{\mathrm{T}^{*}}=\left(\begin{array}{ll}1 & 0 \\ 1 & 1\end{array}\right)$, that's why $\mathrm{e}^{\mathrm{T}} \mathrm{e}^{\mathrm{T}^{*}} \mathrm{e}^{\mathrm{T}^{*}} \mathrm{e}^{\mathrm{T}}=\left(\begin{array}{ll}3 & 4 \\ 2 & 3\end{array}\right)$ and $\mathrm{e}^{\mathrm{T}^{*}} \mathrm{e}^{\mathrm{T}} \mathrm{e}^{\mathrm{T}} \mathrm{e}^{\mathrm{T}^{*}}=\left(\begin{array}{ll}3 & 2 \\ 4 & 3\end{array}\right)$.

Which are not equal, therefore $\mathrm{e}^{\mathrm{T}}$ is not binormal operator.

\section{Definition (2.14)[4]}

An operator T on a Hilbert space H. It is said a hyponormal if $\mathrm{T}^{*} \mathrm{~T}-\mathrm{T}^{*} \mathrm{~T} \geq$ 0 , i.e. $\left\langle\left(T^{*} T-T^{*} T\right) x, x\right\rangle \geq 0, \quad$ for every $\mathrm{x} \in \mathrm{H}$.

\section{Lemma (2.15)}

Let $\mathrm{T}, \mathrm{S}$ be hyponormal operators on $\mathrm{H}$, then:

1. $\alpha \mathrm{T}$ is ahyponormal, for each $\alpha \in \mathbb{C}$

2. If $\mathrm{T}, \mathrm{S}$ are hyponormal operators with the property either commute with adjoint of the other. Then $\mathrm{T}+$ Sishyponormal.

3. If $T_{n}: H \rightarrow H(n=1,2, \ldots)$ is a sequence of hyponormal operator and $T_{n} \rightarrow T$ then Thyponormal.

The proof of this lemma can be found in [2].

\section{Remark (2.16)}

In [5], P.R Halmos gave example of a hyponormal operator $\mathrm{T}$ such that $\mathrm{T}^{2}$ is not hyponormal implies that $\mathrm{T}^{\mathrm{n}}$ may not be a hyponormal for some $\mathrm{n} \geq 2$.

\section{proposition(2.17)}

If $\mathrm{T}$ is a hyponormal and a binormal operator, then $\mathrm{T}^{\mathrm{n}}$ is a hyponormal for $\mathrm{n} \geq 1$.

We can find the proof in [4].

We are going to proof that if $T$ is hyponormal and binormal then $\mathrm{e}^{\mathrm{T}}$ is hyponormal.

\section{Proposition (2.18)}

If $\mathrm{T}$ is a hyponormal and a binormal operator thene ${ }^{\mathrm{T}}$ is hyponormal .

\section{Proof:}

If $\mathrm{T}$ is hyponormal andbinormal operator and $\mathrm{n}$ any positive integer, we have that lemma (2.15) parts (1),(2) and proposition $(2.17)\left(\mathrm{I}+\frac{1}{\mathrm{n}} \mathrm{T}\right)^{\mathrm{n}}$ is a hyponormal. $\operatorname{But}\left(\mathrm{I}+\frac{1}{\mathrm{n}} \mathrm{T}\right)^{\mathrm{n}}$ convergent to $\mathrm{e}^{\mathrm{T}}$ by lemma(2.15) part (3) $\mathrm{e}^{\mathrm{T}}$ is hyponormal.

\section{Definition (2.19)[2]}

An operator $\mathrm{T}$ on a Hilbert space $\mathrm{H}$, is said to be compact if for each bounded sequence $\left(x_{n}\right)$ in $H$, the sequence $\left(\mathrm{Tx}_{\mathrm{n}}\right)$ containsandconvergent subsequence .

\section{Lemma (2.20)[2]}

1. If $\mathrm{T}, \mathrm{S}, \mathrm{U} \in \mathrm{B}(\mathrm{H})$ are compact operators on $\mathrm{H}$, and $\alpha \in \mathbb{C}$, then $\alpha \mathrm{T}$, $\mathrm{T}+\mathrm{S}$ and $\mathrm{U} \mathrm{T}, \mathrm{T} \mathrm{U}$ are compact operators.

2. If $\mathrm{T}$ is a compact operator on $\mathrm{H}$, then $\mathrm{T}^{\mathrm{n}}$ is a compact for any positive integer $\mathrm{n} \geq 2$.

3. If $\left(T_{n}\right)$ is a sequence of compact linear operators on $\mathrm{H}$. Suppose that $T_{n}$ converges to linear operator $\mathrm{T}$, then the operator $\mathrm{T}$ is compact .

\section{Theorem (2.21)}

If $\mathrm{T} \in \mathrm{B}(\mathrm{H})$ is a compact operator. Then:

1. $\mathrm{e}^{\mathrm{T}}$ is compact if $\mathrm{H}$ is finite dimension.

2. $\mathrm{e}^{\mathrm{T}}-\mathrm{I}$ is compact if $\mathrm{H}$ is infinite dimension. 


\section{Proof :}

1.Iis a compact operator since $\mathrm{H}$ is finite dimensional Hilbert space in[2], hence $\mathrm{S}_{\mathrm{n}}=\sum_{\mathrm{k}=0}^{\mathrm{n}} \frac{1}{\mathrm{k} !} \mathrm{T}^{\mathrm{k}}$ is $\quad$ compact operator by lemma (2.20) parts (1) and (2), Therefore $S_{n}$ convergent to the compact operator by (2.20) part ( 3 ), i.e. $\mathrm{e}^{\mathrm{T}}$ is compact.

2. Iis not a compact operator, if $\mathrm{H}$ is infinite dimensional Hilbert space[2] . ButS $_{\mathrm{n}}{ }^{*}=\sum_{\mathrm{k}=1}^{\mathrm{n}} \frac{1}{\mathrm{k} !} \mathrm{T}^{\mathrm{k}} \quad$ is compact operator ifTis compact by lemma (2.20) parts (1)and (2), therefore $\mathrm{e}^{\mathrm{T}}-\mathrm{I}$ is compact .

\section{Remark (2.22)}

1. If $\mathrm{T}$ is a compact operator on infinite dimensional Hilbert space $\mathrm{H}$. Thene $^{\mathrm{T}}$ is not necessary compact, to see this, the $\mathrm{T}=0$ (zero operator) is a compact, where $^{\mathrm{T}}=$ $\mathrm{e}^{0}=$ Iwhich is not compactin [2].

2. If $\mathrm{T}$ is isometric operator on $\mathrm{H}$, then $\|\mathrm{Tx}\|=\|\mathrm{x}\| \forall \mathrm{x} \in \mathrm{H}$. Then $\mathrm{e}^{\mathrm{T}}$ may not be isometric ,to see this, we give the following example:

IfT $=\mathrm{I}$, then $\|\mathrm{T}\|=1$, hence $\left\|\mathrm{e}^{\mathrm{T}}\right\|=$ $\left\|\mathrm{e}^{\mathrm{I}}\right\|=\mathrm{e}\|\mathrm{I}\|=\mathrm{e}$.

3. IfTis a unitary operator on $\mathrm{H}$, then $\mathrm{TT}^{*}=\mathrm{T}^{*} \mathrm{~T}=\mathrm{I}$. thereforee ${ }^{\mathrm{T}}$ may not be unitary to see this,

we give the example:

If $\quad \mathrm{T}=\left(\frac{\sqrt{3}}{2}-\frac{1}{2} \mathrm{i}\right)$ Iand $^{*}=$ $\left(\frac{\sqrt{3}}{2}+\frac{1}{2} \mathrm{i}\right) \mathrm{I}$, implies that $\mathrm{TT}^{*}=$ $\mathrm{T}^{*} \mathrm{~T}=\mathrm{I}$, i.e. Tis unitary operator . We have $\mathrm{e}^{\mathrm{T}}=\mathrm{e}^{\left(\frac{\sqrt{3}}{2}-\frac{1}{2} \mathrm{i}\right) \mathrm{I}}=\mathrm{e}^{\left(\frac{\sqrt{3}}{2}-\frac{1}{2} \mathrm{i}\right)}$ Iand $\mathrm{e}^{\mathrm{T}^{*}}=\mathrm{e}^{\left(\frac{\sqrt{3}}{2}+\frac{1}{2} \mathrm{i}\right) \mathrm{I}}=\mathrm{e}^{\left(\frac{\sqrt{3}}{2}+\frac{1}{2} \mathrm{i}\right)} \mathrm{I} . \quad$ But $\mathrm{e}^{\mathrm{T}} \mathrm{e}^{\mathrm{T}^{*}}=\mathrm{e}^{\sqrt{3}} \mathrm{I} \neq \mathrm{I}$.

\section{The Spectrum of an exponential operator on a} Hilbert space $\mathrm{H}$ :

The spectrum of a linear operator on a Hilbert space $H$, is a subset of the set of complex numbers $\lambda$, for which $\mathrm{T}-\lambda \mathrm{I}$ is not invertible, denoted by
$\sigma(\mathrm{T})$. The complement of the spectrum of linear operator is resolvent, and it is denoted by $\rho(\mathrm{T})$.

\section{Definition (3.1)[2]}

Let $\mathrm{T}$ be a linear operator on a Hilbert space $\mathrm{H}$.

1. The eigenvalue of $\mathrm{T}$ is a complex number $\lambda$, for which $\mathrm{T}-\lambda$ Iis not injective, i.e. There exists a non-zero vector $x$ in $\mathrm{H}$, such that $(\mathrm{T}-\lambda \mathrm{I})(\mathrm{x})=$ 0 , the vector $\mathrm{x}$ is called eigenvector of $\mathrm{T}$ and the set of all eigenvalues of $\mathrm{T}$ denoted by $_{\mathrm{P}}(\mathrm{T})$ is called the set of point spectrum ofT.

2. The continuous spectrum of $\mathrm{T}$, is a set of complex numbers $\lambda$, for which $\mathrm{T}-\lambda$ Iis injective and $\mathrm{T}-\lambda$ Iis not surjective, but the range of $\mathrm{H}$ by linear operator $T-\lambda I$ is dense in $H$. The continuous spectrum of T is denoted by $\sigma_{\mathrm{c}}(\mathrm{T})$.

3. The residual spectrum ofT, is the set of all complex numbers $\lambda$, for which $\mathrm{T}-\lambda$ Iis injective and the range of $\mathrm{H}$ dose not equal $\mathrm{H}$. The residual spectrum of T denoted by $\sigma_{\mathrm{r}(\mathrm{T})}$.

4. The spectral radius of linear operator $\mathrm{T}$ is denoted byr ( $\mathrm{T})$ and it is defined as follows :

$r(T)=\sup _{1}\{|\lambda|, \lambda \in \sigma(T)\}=$
$\lim _{n \rightarrow \infty}\left\|T^{n}\right\|^{\frac{1}{n}}$

\section{Proposition (3.2)}

Let $\mathrm{T} \in \mathrm{B}(\mathrm{H})$ and $\lambda$ be eigenvalue of $\mathrm{T}$, then $\mathrm{e}^{\lambda}$ is eigenvalue of $\mathrm{e}^{\mathrm{T}}$.

\section{Proof:}

There exists a non zero vector $\mathrm{x}$ in $H$, such that $T x=\lambda x($ since $\lambda$ is an eigenvalue of $T$ ), hence $T^{n} x=\lambda^{n} x$. Bute $^{\mathrm{T}} \mathrm{x}=\sum_{\mathrm{n}=0}^{\infty} \frac{1}{\mathrm{n} !} \mathrm{T}^{\mathrm{n}} \mathrm{x}=\sum_{\mathrm{n}=0}^{\infty} \frac{\lambda^{\mathrm{n}} \mathrm{x}}{\mathrm{n} !}=$ $\left(\sum_{n=0}^{\infty} \frac{\lambda^{n}}{n !}\right) x=e^{\lambda} x$.Therefore $e^{\lambda}$ is an eigenvalue of $e^{T}$ and $x$ is a corresponding eigenvector .

\section{Remark (3.3)}

$\operatorname{In}[2]$ E. Kreyszing, provedthat, if $\mathrm{H}$ is finite dimensional Hilbert space. and $\mathrm{T} \in \mathrm{B}(\mathrm{H})$, then $\sigma(\mathrm{T}) \neq \phi$. Furthermore $\lambda \in \sigma(\mathrm{T})$ if and only if $\lambda$ is eigenvalue of 
T. Hence if $\mathrm{H}$ is a finite dimensional Hilbert space then $\lambda \in \sigma\left(\mathrm{e}^{\mathrm{T}}\right)$ if and only if $\lambda$ is eigenvalue of $\mathrm{e}^{\mathrm{T}}$.

In the following example we are going to compute the spectrum of the some linear operators.

\section{Examples (3.4)}

1. $\sigma(\mathrm{I})=\{1\}$, so $\sigma\left(\mathrm{e}^{0}\right)=\sigma(\mathrm{I})=\{1\}$

2. $\sigma\left(\mathrm{e}^{\mathrm{I}}\right)=\sigma(\mathrm{eI})=\{\mathrm{e}\}$.

3. Let $\mathrm{T}$ be a nilpotent operator on a finite Hilbert space $\mathrm{H}$. With order $\mathrm{n}$, we havee ${ }^{\mathrm{T}}=\sum_{\mathrm{k}=0}^{\mathrm{n}-1} \frac{1}{\mathrm{k} !} \mathrm{T}^{\mathrm{k}}$, and $\sigma\left(\mathrm{e}^{\mathrm{T}}\right)=$ $\sigma\left(\sum_{\mathrm{K}=0}^{\mathrm{n}-1} \frac{1}{\mathrm{k} !} \mathrm{T}^{\mathrm{k}}\right)=\left\{\sum_{\mathrm{k}=0}^{\mathrm{n}-1} \frac{1}{\mathrm{k} !} \lambda^{\mathrm{k}}: \lambda \in\right.$ $\sigma(\mathrm{T})\}$ by [2]. But $\sigma(\mathrm{T})=\{0\}$ by [2] , hence $\sigma\left(\mathrm{e}^{\mathrm{T}}\right)=\{1\}$.

\section{Theorem (3.5) [2]}

Let $\mathrm{T}$ be a bounded self-adjoint linear operator on a complex Hilbert space H. Then:

1. The spectrum $\sigma(\mathrm{T})$ is real.

2. The residual spectrum $\sigma_{\mathrm{r}}(\mathrm{T})$ is empty.

3. $\mathrm{r}(\mathrm{T})=\|\mathrm{T}\|$.

\section{Proposition (3.6)}

IfT $\in \mathrm{B}(\mathrm{H})$ and $\mathrm{T}$ is a self-adjoint operator. Then :

1. $\sigma_{\mathrm{P}}\left(\mathrm{e}^{\mathrm{T}}\right)$ subset of real number and $\sigma_{\mathrm{r}}\left(\mathrm{e}^{\mathrm{T}}\right)=\emptyset$

2. $r\left(\mathrm{e}^{\mathrm{T}}\right) \leq \mathrm{e}^{\mathrm{r}(\mathrm{T})}$

\section{Proof:}

1.T is a self-adjoint operator, thene $\mathrm{T}^{\mathrm{T}}$ is self-adjoint by proposition (2.1). Hence $\sigma_{\mathrm{P}}\left(\mathrm{e}^{\mathrm{T}}\right)$ is subset of real number by theorem (3.5) and $\sigma_{\mathrm{r}}\left(\mathrm{e}^{\mathrm{T}}\right)=\varnothing$.

2. By theorem (3.5), we have $r\left(\mathrm{e}^{\mathrm{T}}\right)=$ $\left\|\mathrm{e}^{\mathrm{T}}\right\|$ and by proposition (1.1) part (4), we have $\mathrm{e}^{\|\mathrm{T}\|}=\mathrm{e}^{\mathrm{r}(\mathrm{T})}$

\section{Lemma (3.7) [2]}

$\mathrm{T}$ is a positive self-adjoint if and only if $\sigma(\mathrm{T}) \subseteq[0, \infty)$.

\section{Proposition (3.8)}

If $\mathrm{T}$ is a positive self-adjoint on a complex Hilbert space $H$. Then $\sigma\left(\mathrm{e}^{\mathrm{T}}\right) \subseteq[1, \infty)$.

Proof:
If $\mathrm{T}$ is a positive operator , then $\mathrm{T}^{\mathrm{n}}$ is also positive ( by proposition (2.4) part (4)), i.e. $\left\langle\mathrm{T}^{\mathrm{n}} \mathrm{x}, \mathrm{x}\right\rangle \geq 0$, for $x$ in $H$ and $n$ positive integer. So, we have $<\mathrm{e}^{\mathrm{T}} \mathrm{x}, \mathrm{x}>=<\sum_{\mathrm{n}=0}^{\infty} \frac{1}{\mathrm{n} !} \mathrm{T}^{\mathrm{n}} \mathrm{x}, \mathrm{x}>=$ $\sum_{\mathrm{n}=0}^{\infty} \frac{1}{\mathrm{n} !}<\mathrm{T}^{\mathrm{n}} \mathrm{x}, \mathrm{x}>=\|\mathrm{x}\|^{2}+$ $\sum_{\mathrm{n}=1}^{\infty} \frac{1}{\mathrm{n} !}<\mathrm{T}^{\mathrm{n}} \mathrm{x}, \mathrm{x}>$. Hence $\quad$ inf $\left\{<\mathrm{e}^{\mathrm{T}} \mathrm{x}, \mathrm{x}\right\rangle: \mathrm{x} \in \mathrm{H}$ and $\left.\|\mathrm{x}\|=1\right\} \geq 1$ , then $\sigma\left(\mathrm{e}^{\mathrm{T}}\right) \subseteq[1, \infty)$.

\section{Remarks (3.9)}

1. In [6] M. Akkouch, proves that if $\mathrm{T}$ is a normal operator on $\mathrm{H}$. Then:
1) $\rho(T)=\left\{\lambda: \lambda \in \mathbb{C}, R_{T-\lambda I}=H\right\}$

2) $\sigma_{\mathrm{p}}(\mathrm{T})=\left\{\lambda: \lambda \in \mathbb{C}, \overline{\mathrm{R}_{\mathrm{T}-\lambda \mathrm{I}}} \neq \mathrm{H}\right.$

\}

3) $\sigma_{\mathrm{c}}(\mathrm{T})=\left\{\lambda: \lambda \in \mathbb{C}, \overline{\mathrm{R}_{\mathrm{T}-\lambda \mathrm{I}}}=\mathrm{H}\right\}$

4) $\sigma_{\mathrm{r}}(\mathrm{T})$ is empty.

So, if $\mathrm{e}^{\mathrm{T}}$ is normal operator by proposition (2.8), we have:

1) $\quad \rho\left(\mathrm{e}^{\mathrm{T}}\right)=\left\{\lambda: \lambda \in \mathbb{C}, \mathrm{R}_{\mathrm{e}^{\mathrm{T}}-\lambda \mathrm{I}}=\mathrm{H}\right\}$

2) $\quad \sigma_{\mathrm{P}}\left(\mathrm{e}^{\mathrm{T}}\right)=\left\{\lambda: \lambda \in \mathbb{C}, \overline{\mathrm{R}_{\mathrm{e}^{\mathrm{T}}-\lambda \mathrm{I}}} \neq \mathrm{H}\right\}$

3) $\sigma_{\mathrm{c}}\left(\mathrm{e}^{\mathrm{T}}\right)=\left\{\lambda: \lambda \in \mathbb{C}, \overline{\mathrm{R}_{\mathrm{e}^{\mathrm{T}}-\lambda \mathrm{I}}}=\mathrm{H}\right\}$

4) $\quad \sigma_{\mathrm{r}}\left(\mathrm{e}^{\mathrm{T}}\right)$ is empty.

2. In [6], we have if $T$ is a normal operator on a Hilbert space $\mathrm{H}$, then $r(\mathrm{~T})=\|\mathrm{T}\|$, so $\quad r\left(\mathrm{e}^{\mathrm{T}}\right)=\left\|\mathrm{e}^{\mathrm{T}}\right\| \leq$ $\mathrm{e}^{\mathrm{r}(\mathrm{T})}$, (because $\mathrm{e}^{\mathrm{T}}$ is normal if $\mathrm{T}$ is a normal by proposition (2.8)) .

3. In [7], we have if $T$ is a hyponormal operator, then $\sigma(\mathrm{T})=$ $\sigma_{\mathrm{P}}\left(\mathrm{T}^{*}\right)$. Hence $\sigma\left(\mathrm{e}^{\mathrm{T}}\right)=\sigma_{\mathrm{P}}\left(\mathrm{e}^{\mathrm{T}^{*}}\right),($ because $\left(\mathrm{e}^{\mathrm{T}}\right)$ is hyponormal if $\mathrm{T}$ is hyponormal and binormal by proposition (2.19)) .

4. In [8], we have if $\mathrm{T}$ is a hyponormal operator on a Hilbert space $\mathrm{H}$, the $\mathrm{r}(\mathrm{T})=\|\mathrm{T}\|$, thereforer $\left(\mathrm{e}^{\mathrm{T}}\right)=\left\|\mathrm{e}^{\mathrm{T}}\right\| \leq \mathrm{e}^{\mathrm{r}(\mathrm{T})}$ because $^{\mathrm{T}}$ is hyponomral if ( Tis hyponormal and binormal by proposition (2.19)) .

\section{References:}

1.Mariano Giaquinta; GiueppeModica. 2007. Mathematical analysis linear and Metric structure and continuity. Springer, Italy, PP 465. 
2. E. Kreyszing . 2010. Introductory to functional Analysis with application, john weily and sons. PP: 688

3. S.Panayappan ${ }^{1}$ and N. Sivamani ${ }^{2}$. 2012. A-Qusinormal operators in semiHilbertian space, Gen. Math. Notes . 10 (2):30-35

4.Raghad ,Ehsan ; AL- Sultan. 2000. Some generalization of normal operators. A Master thesis Department Mathematics, College of Science, Baghdad University. PP: 56.
5. P. R. Halmos.1967. A Hilbert space problem book. Springer verlag, New York. PP 367.

6.Akkouch , I. M. 2008. Remarks on spectrum of bounded and normal operator on a Hilbert space, An . St. 16(2): 7-14.

7.Sheth , I . H .1966. On hyponormaloperators ,Proc .Amer .Math .Soc , 17:998-1001.

8.Eman , H. Al Ganabi .1996. Numerical range and normal operators.A master thesis, Department Mathematics, College of science, University of Baghdad. PP: 82

\section{الأله الأسيه لمؤثز خطي مقيا علنضاء هلبرث \\ فاتن عباس /حمد*

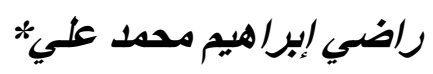 \\ *قمم الرياضيات ،كلية العلوم للبنات ،جامعة بغداد.}

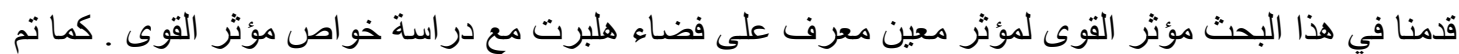

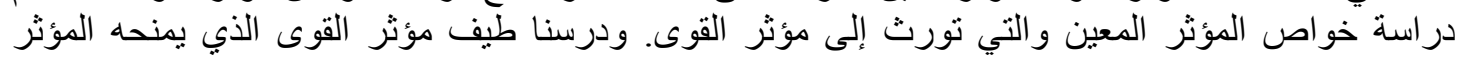

